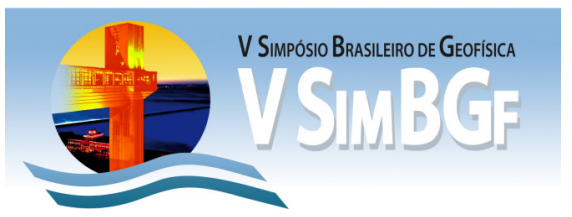

\title{
Modelagem geológica de alta resolução de depósitos costeiros no sul do Estado do Espírito Santo: Contribuição para o entendimento da dinâmica sedimentar durante 0 Holoceno
}

\author{
Arthur Bazoni da Fonseca, Felipe Guadagnin - Universidade Federal do Espírito Santo
}

Copyright 2012, SBGf - Sociedade Brasileira de Geofísica

Este texto foi preparado para a apresentação no V Simpósio Brasileiro de Geofísica, Salvador, 27 a 29 de novembro de 2012. Seu conteúdo foi revisado pelo Comitê Técnico do V SimBGf, mas não necessariamente representa a opinião da SBGf ou de seus associados. É proibida a reprodução total ou parcial deste material para propósitos comerciais sem prévia autorização da SBGt.

\section{Resumo}

Apresentamos modelo geológico de alta resolução, de sedimentos costeiros de idade holocênica, no sul do Estado do Espírito Santo. O modelo foi gerado a partir de dados de GPR e testemunhos de sondagem. Os dados apresentados permitem derivar as variações eustáticas de alta frequência ( $4^{\mathrm{a}}$ a $5^{\mathrm{a}}$ ordens) e o padrão de dispersão dos sedimentos costeiros durante o holoceno.

\section{Introdução}

A literatura é consensual quando trata dos fatores que controlam a ciclicidade da deposição de sequências de sedimentos siliciclásticos em bacias sedimentares. São necessários, em primeira instância, espaço para a acumulação dos sedimentos (i.e. a bacia sedimentar) e aporte de sedimentos clásticos terrígenos. O espaço de acomodação é controlado tanto por movimentos verticais na crosta terrestre (tectônica) quanto por oscilações eustáticas; e o aporte de sedimentos clásticos terrígenos é controlado por uma série de fatores, destancando as condições climáticas da área fonte (Ribeiro, 2001; Boggs, 2009; Catuneanu et al., 2009; entre outros).

A planície costeira do sul do Estado do Espírito Santo corresponde a porção superior, aflorante, da Bacia de Campos. É formada pelos sedimentos e rochas sedimentares pouco consolidadas do Paleogeno Médio ao Neogeno Superior (Grupo Barreiras), depositados em ambiente fluvial (Morais et al., 2006); e por sedimentos holocênicos, de origem aluvial-fluvial, estuarina, deltaica e costeira (Fig. 1).

Existem indícios que apontam para um controle tectônico na evolução da região costeira do Sudeste do Brasil durante o Cenozóico (Riccomini, 1989; Cobbold et al., 2001; Hatushika et al., 2007; Cogné et al., 2011), que estão além dos objetivos do presente trabalho.

Além do provável controle tectônico, os eventos de transgressão e regressão marinha ocorridos do Mioceno ao Recente são os principais responsáveis pela construção da planície costeira do Sudeste do Brasil (Martin, 2003; Arai, 2006).

No presente trabalho realizamos investigação geológicageofísica de alta resolução em depósitos costeiros do sul do Estado do Espírito Santo, com o objetivo de gerar um modelo geológico de sub-superfície e derivar os padrões de preenchimento sedimentar durante o Holoceno.
Especificamente são objetivos do presente trabalho: i) investigar as variações eustáticas de $4^{\mathrm{a}}$ a $5^{\mathrm{a}}$ ordem, que são responsáveis pelo desenvolvimento de parassequências costeiras; e ii) definir o sentido das paleocorrentes longitudinais a linha de costa atual, entre os deltas dos rios Itapemirim e Itabapoana (Fig. 1).

\section{Metodologia/ Problema Investigado}

Foi selecionada uma área de aproximadamente 31.500 $\mathrm{m}^{2}$ localizada entre os deltas dos rios Itapemirim e Itabapoana, no município de Marataízes, ES (Fig. 1). A área de estudo situa-se entre os platôs costeiros formados pelo Grupo Barreiras, e a linha de costa atual. Os platôs ocorrem em cotas que atingem até $40 \mathrm{~m}$ enquanto que os sedimentos holocênicos não passam de $15 \mathrm{~m}$ acima do nível do mar. As falésias do Grupo Barreiras distam entre 250 e 300m da linha de costa. Os sedimentos holocênicos se encontram em onlap no Grupo Barreiras.

Para geração do modelo geológico foram realizadas etapas de aquisição de dados em campo e de processamento e interpretação dos dados em laboratório.

Em campo foram efetuados três procedimentos: i) levantamento topográfico; ii) aquisição geofísica; e iii) sondagem.

O levantamento topográfico foi efetuado por meio da determinação das coordenadas espaciais $X, Y, Z$ de 73 pontos de controle, com o uso de Estação Total e DGPS.

A aquisição geofísica foi realizada com Radar de Penetração no Solo (GPR) pelo método commom offset. O GPR utilizado foi equipado com antena monoestática de 200 Mhz. Fixou-se o tempo de amostragem em 200 ns, obtendo-se 50 leituras por metro, com taxa de amostragem de 1024. Aplicou-se um ganho de campo para visualização dos dados em tempo real. Foram adquiridos 9 radargramas na direção $E-W$, transversais a linha de costa (seções dip), e 4 radargramas $\mathrm{N}-\mathrm{S}$, paralelos a costa (seções strike) (Fig. 2).

Foi gerada uma malha relativamente regular de 12 pontos afastados em média $50 \mathrm{~m}$ cada, dispostos em 3 linhas E-W por 4 linhas N-S. Em cada um dos 12 pontos foram coletados testemunhos de sondagem rasa (até $2 \mathrm{~m}$ ) pelo método percussivo, utilizando-se canos de PVC.

A figura 2 corresponde ao mapa do levantamento, onde são ilustrados os radargramas adquiridos, as curvas de nível da topografia e locação dos poços testemunhados. 


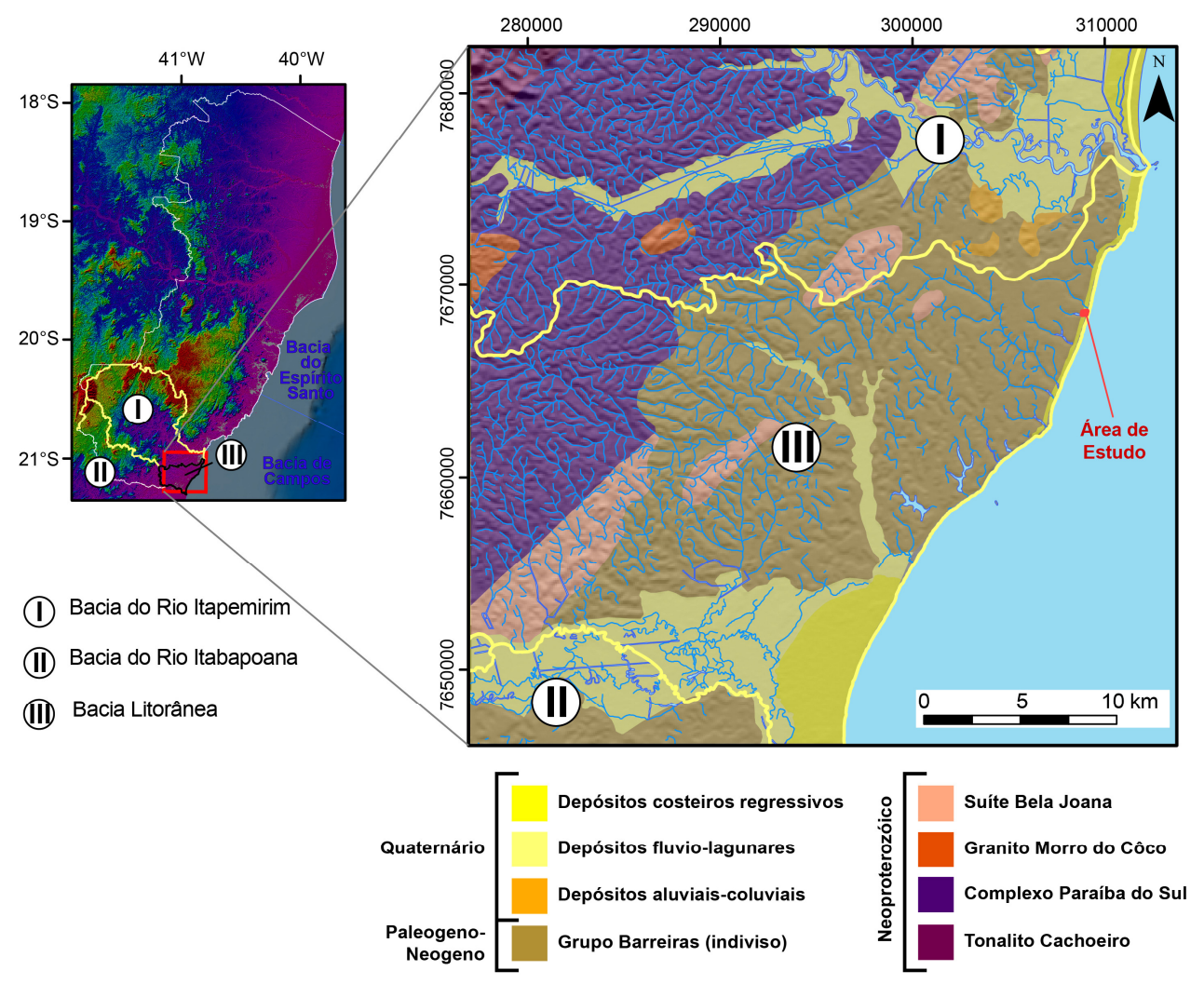

Figura 1 - Localização da área de estudo. A esquerda é mostrado o Modelo Digital do Terreno da área do Estado do Espírito Santo (em branco). As áreas em amarelo delimitam as bacias hidrográficas dos rios Itapemirim (I) e Itabapoana (II). A área delimitada pelo polígono em preto (III) corresponde à bacia Litorânea. A localização do mapa geológico é destacada. A direita é representado o mapa geológico de parte da planície costeira do sul do Estado do Espírito Santo. A área do presente estudo é ilustrada em vermelho (modificado de Silva, 2004).

O processamento dos dados de campo consistiu em 3 etapas: i) geração do Modelo Digital do Terreno (MDT); ii) processamento dos dados de radar; iii) descrição dos testemunhos de sondagem.

Com as coordenadas $\mathrm{XYZ}$ dos 73 pontos obtidos em campo, foi aplicado um algoritmo de interpolação com o objetivo de gerar uma superfície tridimensional que representa o MDT.

Os dados de radar foram processados de acordo com o fluxograma mostrado na figura 3 . A restauração do ganho de campo foi realizada com o objetivo de obter o dado original, sem nenhum ganho aplicado. A filtragem de frequência foi realizada pela aplicação de um filtro passa alta com 50 Mhz para remover o sinal de baixa frequência e um filtro passa baixa com $600 \mathrm{Mhz}$ para remover o ruído eletrônico (Wow). A correção topográfica corrige os efeitos do relevo e posiciona os refletores na sua posição vertical correta. A correção para a topografia foi realizada utilizando os dados do MDT. Foi aplicado ganho automático (automatic gain control - AGC) para ressaltar de forma homogênea as feições em profundidade e ganho linear de $7 x$ para ressaltar as feições em toda a seção. $O$ procedimento de migração foi realizado para posicionar os refletores mergulhantes na sua correta posição horizontal e vertical, remover distorções estruturais associadas com refletores ondulantes e remover as difrações. A conversão de tempo em profundidade foi realizada pelo método da velocidade constante.

$$
\begin{aligned}
& V=\sim 0,13 \mathrm{~m} / \mathrm{ns} \\
& \varepsilon=\sim 0,58 \\
& P=\sim 12 \mathrm{~m}
\end{aligned}
$$

A velocidade de propagação da onda de radar foi calculada pelo método direto, em campo, utilizando um cano de ferro enterrado a profundidade de $0,38 \mathrm{~m}$. Foi adquirido um radargrama sobre o cano soterrado, obtendo-se aproximadamente 13ns de tempo de deslocamento duplo. A velocidade calculada é de $0,13 \mathrm{~m} / \mathrm{ns}$, que coincide com os valores de areia costeira seca disponíveis na literatura (velocidade de 0,095 a 0,134 m/ns - Reynolds, 2011). 


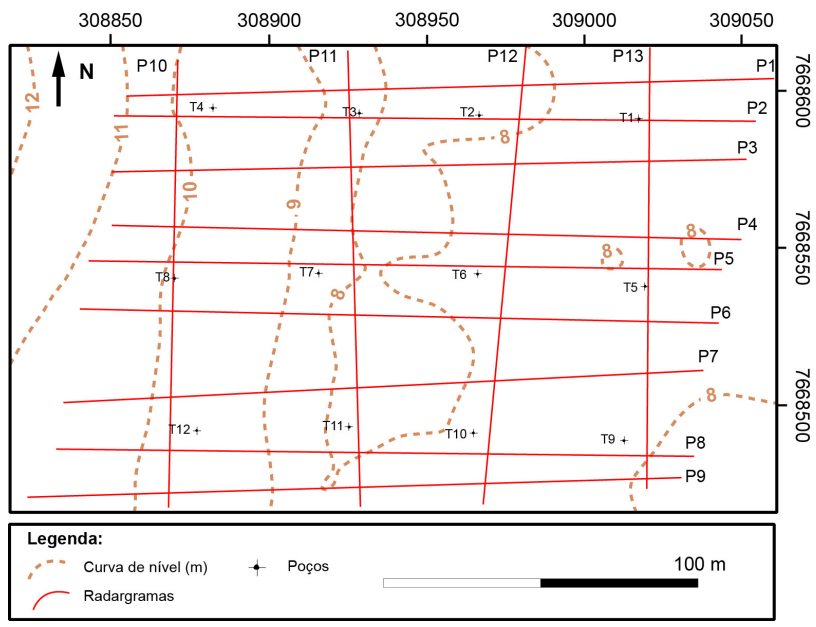

Figura 2 - Mapa do levantamento geofísico e sondagens.

O último passo no processamento dos dados de radar é a rasterização dos radargramas, convertendo os mesmos para o formato bitmap (bmp), para a inserção em software de modelagem.

A descrição dos testemunhos de sondagem foi iniciada pela abertura dos testemunhos empregando a técnica descrita por Martin et al. (1995). Cortaram-se os testemunhos longitudinalmente utilizando uma serra circular diamantada. Com um fio de nylon ao longo do testemunho, foi realizada a separação dos dois semicilindros. Após esse procedimento foi realizada a descrição sedimentológica visual com o uso de lupa e cartela granulométrica. Foram descritas as principais fácies e determinadas as suas espessuras. Posteriormente foi gerado um log de cada "poço".

Os dados processados foram inseridos em programa de modelagem, a saber: i) superfície topográfica (MDT); ii) radargramas processados; iii) localização e log dos testemunhos de sondagem. A superfície topográfica foi inserida por meio de um arquivo raster com resolução espacial de $30 \mathrm{~cm}$. Os radargramas foram inseridos como raster (bmp), com as coordenadas iniciais e finais obtidas com GPS de navegação e profundidade calculada na etapa de processamento. Os logs dos "poços" foram inseridos como um arquivo de texto com as coordenadas da "cabeça" do poço obtidas com DGPS e as fácies sedimentares com suas respectivas espessuras.

Foram traçados os refletores de cada um dos 13 radargramas, utilizando ferramentas de modelagem de horizontes estratigráficos. O horizonte correspondente ao freático foi traçado. Os dados geofísicos foram correlacionados com os testemunhos. Foram delimitados tratos de sistemas delimitados por superfícies chave (Fig. 7).

\section{Resultados}

Os testemunhos de sondagem alcançaram uma profundidade máxima de $2 \mathrm{~m}$. Sendo assim, somente 0 topo das seções de radar foi amostrado (Fig. 7a e b).

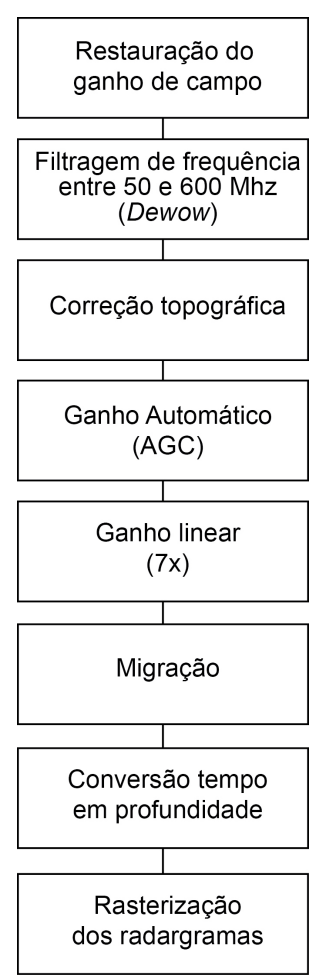

Figura 3 - Fluxograma do processamento dos dados de GPR.

Observou-se uma tendência homogênea em todos os 12 testemunhos amostrados. De modo geral, os sedimentos apresentam composição quartzosa, com granulometria variando de areia média à grossa, moderadamente selecionada e arredondamento variando de subangular a subarredondado. Os sedimentos possuem alta maturidade composicional e são maduros a supermaduros texturalmente.

Foram identificadas três fácies sedimentares: fácies I, II e III. A fácies I é composta por areia ligeiramente mais grossa que as demais, caracterizada como areia grossa superior à muito grossa, levemente mal selecionada $\mathrm{e}$ subangular. A fácies II é caracterizada por areia grossa superior, moderadamente selecionada e subarredondada. A fácies III apresenta gradação normal passando de areia média superior a areia média, moderadamente selecionada e subangular. A fácies I não foi observada nos testemunhos 4, 8, 11 e 12, possivelmente devido a cota topográfica mais elevada destes testemunhos (Fig. 2).

Os radargramas atingiram a profundidade média de 12 metros. Nos radargramas adquiridos, tanto nas seções dip quanto nas strike, o refletor que corresponde ao lençol freático apresentou-se bem marcado, resutaldo do forte contraste dielétrico na interface entre areia saturada em água e a não saturada.

Foram identifcadas duas radarfácies: Radarfácies (R1) Compreendem refletores subparalelos e ondulados, truncados, com terminações em onlap com os refletores 
abaixo, mostrando padrão agradacional e retrogradacional, denotando padrão transgressivo.

Radarfácies Oblíqua Tangencial (R2) - Caracteriza-se por refletores mergulhantes descontínuos, com terminações em downlap. O mergulho do foreset descrece gradualmente na porção inferior. Apresentam padrão de progradacional. Por vezes são identificados refletores em offlap.

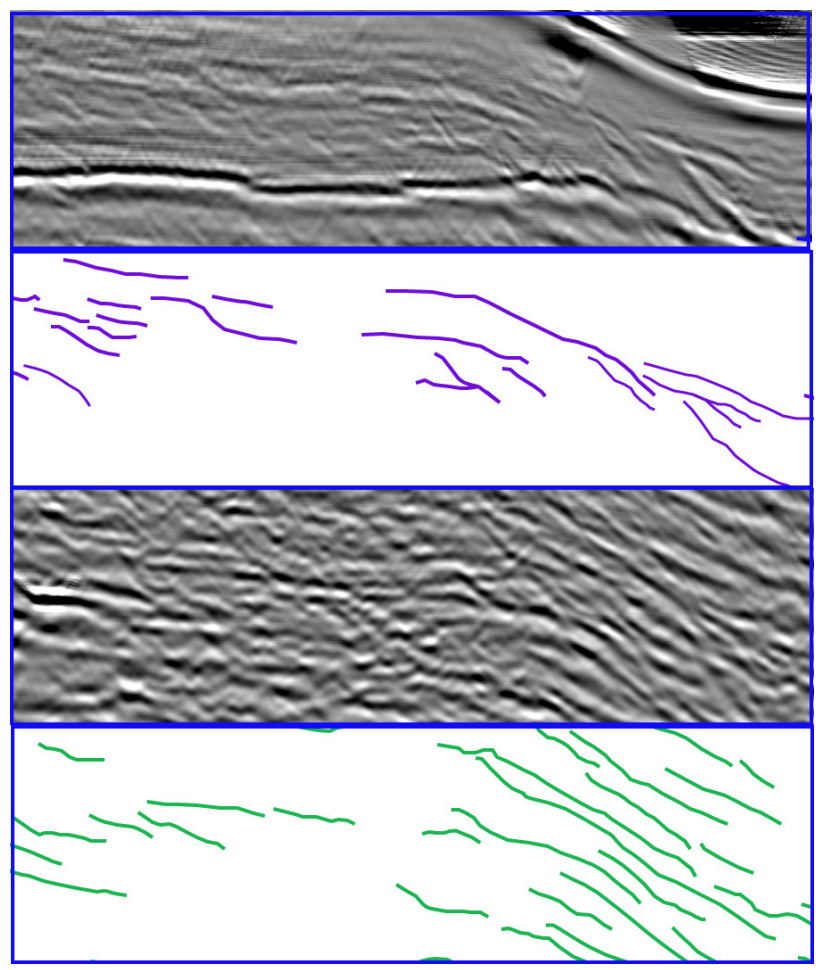

Figura 4 - Radarfácies identificadas. R1 abaixo e R2 acima.

A radarfácies $\mathrm{R} 1$ ocorre sistematicamente na base dos radargramas adquiridos, enquanto que a radarfácies R2 ocorre na porção superior. Nas seções strike, a radarfácies R2 mostra padrão progradacional com paleocorrente para sul. Nas seções dip as paleocorrentes são para leste (Fig. 6).

Devido a esse padrão, foi possível traçar a superfície transgressiva (ST) nos radargramas strike. Essa superfície corresponde a superfície de ravinamento por onda (Fig. 7) (Johnston et al., 2007). Nos radargramas ela corresponde a superfície de downlap ou seja, a superfície de maior ordem onde os refletores da radarfácies R2 terminam. Somente na seção 5 não foi possível identificar fielmente a ST. A partir da ST traçada em 8 radargramas, foi gerada uma superfície tridimensional (Fig. 7d).

Foram gerados dois volumes geológicos com base nas superfícies: i) base da seção; ii) superfície transgressiva; e iii) superfície topográfica;. $O$ volume inferior corresponde a seção transgressiva e o volume superior a sequência regressiva (Fig. $7 d$ ).

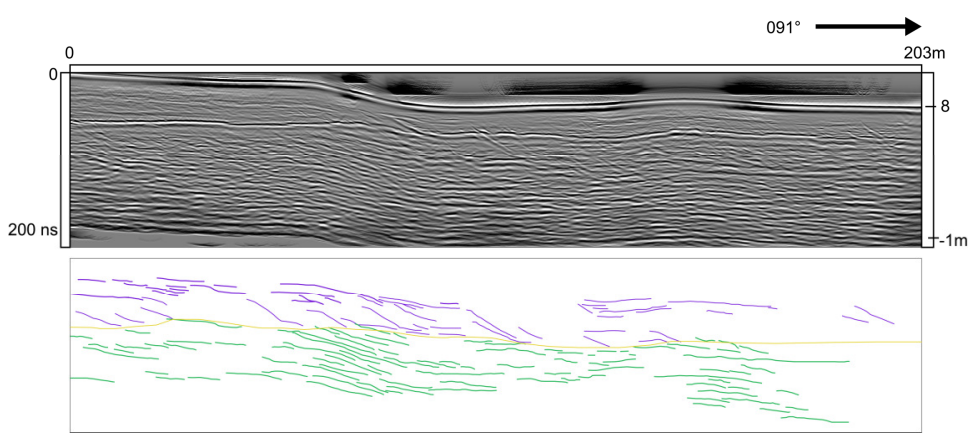

Figura 5 - Radargrama P8. São mostrados os refletores interpretados, evidenciando padrão transgressivo na porção basal e regressivo na porção superior.

\section{Discussão e Conclusões}

Os dados aqui apresentados nos permitem interpretar o padrão de preenchimento da faixa costeira entre as falésias do Grupo Barreiras e a linha de costa atual durante o Holoceno. Além disso, as variações eustáticas de alta frequência $\left(4^{\mathrm{a}}\right.$ a $5^{\mathrm{a}}$ ordens) e os vetores de dispersão de sedimentos costeiros (correntes litorâneas) são apresentados.

$\mathrm{Na}$ porção inferior dos radargramas de direção dip são identificados refletores em padrão transgressivo (onlap retrogradacional), enquanto que na porção superior, os refletores identificados mostram padrão regressivo (cunhas sigmoidais progradantes e refletores em offlap). O padrão transgressivo é produto da subida do nível do mar durante o holoceno, a partir do último período glacial a 7.000 anos, quando o nível do mar se encontrava a 120 $\mathrm{m}$ abaixo do nível atual. $\mathrm{O}$ padrão regressivo na porção superior é oriundo do aporte sedimentar clástico dos deltas dos rios Itapemirim e Itabapoana. Com base no exposto, interpretamos um trato de sistemas transgressivo seguido de um trato de regressão normal (sensu Catuneanu et al., 2009), ambos na 4a ordem de ciclicidade.

Ainda, é notável um padrão de alta frequência $(5 a$ ordem), principalmente no trato de regressão normal. Tal padrão é identificado em refletores contínuos abaixo e refletores em offlap e downlap acima. O padrão de alta frequência ( $5 \mathrm{a}$ ordem) pode ter origem alocíclica (ciclos climáticos - Milankovich) ou autocíclica (variação na taxa de sedimentação; ambiente costeiro-marinho raso depósitos de tempestade), e necessita maior investigação.

Com relação as correntes litorâneas, as seções strike mostram progradações para Sul (paleocorrentes). Essa informação implica no padrão de deriva litorânea no holoceno (Fig. 6). As seções dip mostram progradações para Leste, indicando que os depósitos são regressivos. A regressão é normal (cunhas sigmoidais) na maior parte dos refletores, sendo que alguns mostram padrão de regressão forçada (offlap). 
A variação eustática de alta frequência durante o holoceno é conhecida para a região leste do Brasil (Sugio et al., 1988; Martin, 2003). A investigação detalhada da região costeira do sul do Estado do Espírito Santo pode auxiliar na definição dos padrões de onlap costeiro e, por sua vez, na curva eustática do holoceno.

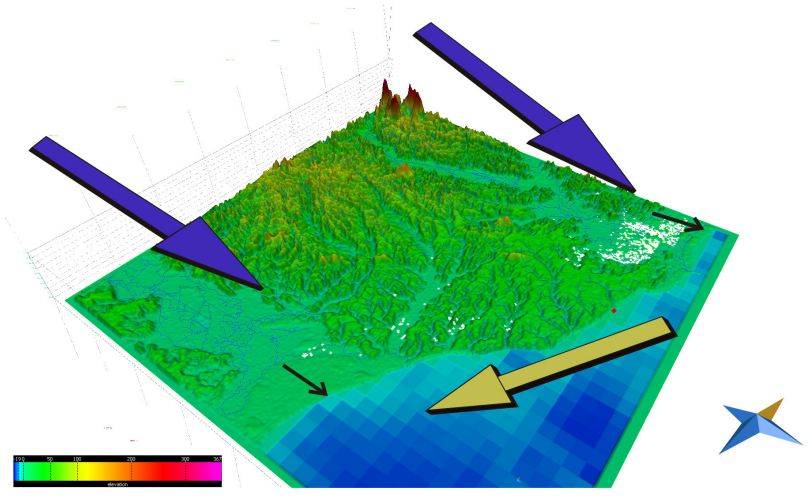

Figura 6 - Modelo de dispersão de sedimentos costeiros na área de estudo. A figura mostra uma vista oblíqua de SE para NW do Modelo Digital do Terreno (SRTM, exagero vertical de 10x) e Batimetria (GEBCO). A área representada é a mesma que a da figura 1. Os vetores azuis ilustram o principal aporte de sedimentos continentais na região (Rios Itapemirim e Itabapoana), e o vetor amarelo representa o padrão da deriva de corrente litorânea (corrente paralela a linha de costa), que é de Norte para Sul. As linhas pretas mostram o padrão de desenvolvimento dos cordões litorâneos regressivos. A área do levantamento é ilustrada em vermelho.

\section{Referências}

Arai, M., 2006. A grande elevação eustática do Mioceno e sua influência na origem do Grupo Barreiras. Geol. USP Sér. Cient. 6, 1-6.

Boggs, S.Jr., 2009. Petrology of Sedimentary Rocks. Cambridge: Cambridge University Press, 2 ed. 600 p.

Catuneanu et al., 2009. Toward the standardization of sequence stratigraphy. Earth Science Reviews 92, 1-33.
Cobbold, P., Meisling, K., Mount, V., 2001. Reactivation of an obliquely rifted margin, Campos and Santos basins, southeastern Brazil. AAPG Bulletin 85, 1925-1944.

Cogné, N., Gallagher, K., Cobbold, P., 2011. Post-rift reactivation of the onshore margin of southeast Brazil: Evidence from apatite (U-Th)/He and fission-track data. Earth and Planetary Science Letters 309, 118-130.

Hatushika, R., Silva, C., Mello, C., 2007.

Sismoestratigrafia de alta resolução no lago Juparanã, Linhares (ES-Brasil) como base para estudos sobre a sedimentação e tectônica quaternária. Revista Brasileira de Geofísica 25, 433-442.

Johnston, J.W., Thompson, T.A., and Baedke, S.J., 2007, Systematic pattern of beach-ridge development and preservation: Conceptual model and evidence from ground penetrating radar, in Baker, G.S., and jol, H.M., eds., Stratigraphic Analyses Using GPR: Geological Society of America Special Paper 432, p. 47-58.

Martin, L., 2003. Holocene sea-level history along eastern-southeastern Brazil. Anuário do Instituto de Geociências - UFRJ 26, 13-24.

Martin, L., Flexor, J., Suguio, K., 1995.

Vibrotestemunhador leve: construção, utilização e possibilidades. Revista Instituto de Geociências 16, 5966.

Morais, R., Mello, C., Costa, F., Santos, P., 2006. Fácies sedimentares e ambientes deposicionais associados aos depósitos da Formação Barreiras no Estado do Rio de Janeiro. Revista do Instituto de Geociências - USP 6, 19 30.

Reynolds, J., 2011. An introduction to applied and environmental geophysics. Chichester: Wiley-Blackwell, 2 ed., cap. 13, p. 535-564.

Ribeiro, H., 2001. Estratigrafia de sequências: fundamentos e aplicações. São Leopoldo: Unissinos. 428 p.

Riccomini C., Peloggia A.U.G., Saloni J.C.L., Kohnke M.W., Figueira R.M. 1989. Neotectonic activity in the Serra do Mar rift system (southeastern Brazil). Journal of South American Earth Sciences, 2(2): 191 -197.

Silva, M., 2004. Folha Vitória SF-24. CPRM, Mapa geológico na escala 1:1.000.000. 




Figura 7 - Modelo tridimensional gerado a partir dos dados adquiridos. Em A é mostrada a superfície topográfica com os radargramas e os testemunhos de sondagem. Em $B$ a projeção das fácies identificadas nos testemunhos de sondagem; em Cos refletores e superfícies interpretadas. Em D é representada a superfície transgressiva, em $E, F$ e G, os volumes gerados, entre a superfície de base da seção e a superfície topográfica $(E$ e $F)$ e entre a superfície transgressiva e a topográfica (G). Em H é mostrada uma vista do radargrama $P 7$, com a projeção dos testemunhos e as superfície topoaráfica e transaressiva. 